\title{
Coxiella burnetii ( $Q$ fever) infection in dairy cattle and associated risk factors in Latvia
}

\author{
A. BORODUSKE, J. TROFIMOVA, J. KIBILDS, U. PAPUlE, M. SERGEJEVA, \\ I. RODZE AND L. GRANTINA-IEVINA*
}

Animal Disease Diagnostic Laboratory, Institute of Food Safety, Animal Health and Environment "BIOR”, Riga, Latvia

Received 6 June 2016; Final revision 24 March 2017; Accepted 28 March 2017;

first published online 2 May 2017

\section{SUMMARY}

The purpose of this study was to describe prevalence and spatial distribution of Coxiella burnetii infections in dairy cow sheds in Latvia and to investigate risk factors contributing to C. burnetii infections. Blood serum samples from abortion cases from 1010 sheds have been tested by ELISA for the presence of C. burnetii antibodies and bulk tank milk (BTM) samples from 252 sheds have been tested by real time polymerase chain reaction and ELISA for the presence of C. burnetii DNA and antibodies. Prevalence of $C$. burnetii antibody-positive sheds in cases of abortion was $13 \cdot 4 \%$. A total of $10 \cdot 7 \%$ and $13 \cdot 2 \%$ of dairy cow sheds tested positive for the presence of $C$. burnetii DNA and antibodies in BTM, respectively. Two distinct areas of clustering of test-positive dairy cattle sheds were identified by spatial scan statistics of abortion cases and randomly sampled BTM samples. Three factors were identified as significantly contributing to the risk of $C$. burnetii DNA presence in BTM - number of cattle in shed (>200 animals/shed) (OR 3.93), location of the shed within risk area in Northern Latvia (OR 8.29) and for the first time, purchasing cattle from abroad has been shown to significantly increase risk (OR 2.68) of C. burnetii infection in dairy cows in Latvia.

Key words: ELISA, Q fever, risk assessment, serology, zoonoses.

\section{INTRODUCTION}

Coxiella burnetii - a gram-negative intracellular bacterial pathogen is the causative agent of $\mathrm{Q}$ fever - a widespread zoonotic disease. Although the number of acute human infections in the majority of European countries remains confined to $<100$ cases/year [1], local outbreaks are not uncommon in western, central and southern Europe. Domestic ruminants have been the main

\footnotetext{
* Author for correspondence: L. Grantina-Ievina, Animal Disease Diagnostic Laboratory, Institute of Food Safety, Animal Health and Environment "BIOR", Lejupes Street 3, Riga, LV-1076, Latvia.

(Email: lelde.grantina-ievina@bior.lv)
}

source of human infections during latest outbreaks of Q fever [2-4], therefore surveillance of C. burnetii infections in domestic animals can also serve as a precautionary measure for prevention of $\mathrm{Q}$ fever outbreaks in humans.

The majority of reported outbreaks of $\mathrm{Q}$ fever in humans in Germany, UK and The Netherlands have been associated with ovine and goat abortion waves and high prevalence of infections in small domestic ruminants $[2,4,5]$. Although large outbreaks have rarely been associated with cattle farming (except for Poland [6]), molecular genotyping data does not exclude cattle as a possible reservoir of $C$. burnetii strains infectious to humans [7]. Studies of seroprevalence in persons 
occupationally associated with cattle farming have revealed a significant proportion of seropositive individuals, suggesting that cattle-human contact can be a common route of infection $[8,9]$.

Animal birth products either from abortions or normal deliveries pose the highest risk for animal and human infections due to a high load of $C$. burnetii in placental tissues [10]. Aerosols containing airborne particles from ruminant farms, especially animal birthing places and farms with high ruminant abortion rates are considered to pose the highest risk for human infection [11, 12]. Increased risk of C. burnetii infections in animals has previously been associated with local agricultural practice related factors - such as regional herd density [13], herd size [14-16], animal housing system [15, 17], animal movements [13, 18], C. burnetii prevalence in goats [3] and sheep [7], hygiene practice [18, 19] as well as climatic and geographical characteristics of the region, for example wind [13, 20, 21]. Thus, factors primarily associated with increased risk of $\mathrm{Q}$ fever infections are locally and regionally specific, imposing a need for regional assessments of $\mathrm{Q}$ fever spread and associated factors.

Probably due to a low incidence rate of $C$. burnetii infection in humans, information regarding $Q$ fever epidemiology in domestic animals in north-eastern Europe is scarce and confined to seroprevalence data included in national and EU reports. Dairy cattle farming is a predominant branch of animal husbandry in Latvia with 25000 cattle sheds reported in 2015 [22]. Surveillance based on ELISA of C. burnetii prevalence in cattle in Latvia has identified 14.6\% and $10.3 \%$ seropositive cattle abortion cases in 2012 and 2013, respectively [23]. In the time period from 2008 till 2012 there have been five officially registered cases of Q- fever in humans in Latvia [23]. Although seroprevalence data from cattle abortion cases suggests that a certain part of the Latvian dairy cattle population is infected by $C$. burnetii, spatial epidemiology, overall prevalence at herd level or associated risk factors have not been assessed previously. The present study analyses abortion-related and overall prevalence of $C$. burnetii infections in dairy cattle in Latvia based on three diagnostic parameters: presence of $C$. burnetii DNA in bulk tank milk (BTM), immunological response to C. burnetii in BTM and immunological response in blood serum. In addition, factors associated with increased risk of $C$. burnetii infections in cattle in Latvia are assessed. To the best of our knowledge, this is the first study reporting
C. burnetii prevalence in dairy cattle and associated risk factors in any of the Baltic countries.

\section{MATERIALS AND METHODS}

\section{Sample collection}

In total 2088 dairy cow blood samples representing 1010 dairy cattle sheds were sampled during 4 year period of 2012-2015 (Table 1). All samples were collected from cases of cattle abortions under the national dairy cattle abortion surveillance program. Dairy cattle shed were used as the unit of analysis for herd level prevalence assessment and a given shed was considered seropositive if at least one blood serum sample originating from the shed tested positive. The term 'shed' is used in official statistics by the Agricultural Data Center of Latvia. The term 'herd' is used to describe the total number of cattle owned by a single owner. However, animals belonging to the same herd can be kept in different sheds sometimes distantly located. Thus, the term 'herd' is more related to ownership of animals rather than the functional unit therefore, it was considered that 'shed' is a more appropriate unit of analysis rather than 'herd'. Data from cow sheds that were represented by more than five independent abortion cases during sampling period (68 sheds in total) was used for within-herd seroprevalence assessment.

A total of 346 BTM samples from 252 dairy cattle sheds initially submitted under the national programme of bovine leucosis virus and Brucella sp. surveillance during the 6 month period of July-December 2015 were included in the analysis (Table 2). There are significant differences in total number of animals held by different sheds included in the study. Although the guidelines of BTM sample collection did not specify number of animals per sample or number of samples per shed, in general veterinary practitioners have collected more samples from sheds with larger total number of animals and only one or few samples from small sheds (total number of animals and number of BTM samples collected have strong correlation - Pearsons's linear coefficient $R^{2}=0.855, P<0 \cdot 05$ (data not shown)).

Analysed samples represent $5 \%$ of all Latvian dairy cattle sheds.

\section{Assays for $C$. burnetii infection and seropositivity}

Presence of C. burnetii DNA in BTM samples was determined by quantitative polymerase chain reaction 
Table 1. Number of cows (blood samples) tested in each dairy cattle shed

\begin{tabular}{|c|c|c|c|c|c|c|c|c|}
\hline \multirow{2}{*}{$\begin{array}{l}\text { Year } \\
\text { Number of } \\
\text { samples from } \\
\text { one shed }\end{array}$} & \multicolumn{2}{|l|}{2012} & \multicolumn{2}{|l|}{2013} & \multicolumn{2}{|l|}{2014} & \multicolumn{2}{|l|}{2015} \\
\hline & $\begin{array}{l}\text { Number of } \\
\text { sheds }\end{array}$ & $\begin{array}{l}\text { Total } \\
\text { number of } \\
\text { samples }\end{array}$ & $\begin{array}{l}\text { Number of } \\
\text { sheds }\end{array}$ & $\begin{array}{l}\text { Total } \\
\text { number of } \\
\text { samples }\end{array}$ & $\begin{array}{l}\text { Number of } \\
\text { sheds }\end{array}$ & $\begin{array}{l}\text { Total } \\
\text { number of } \\
\text { samples }\end{array}$ & $\begin{array}{l}\text { Number of } \\
\text { sheds }\end{array}$ & $\begin{array}{l}\text { Total } \\
\text { number of } \\
\text { samples }\end{array}$ \\
\hline 1 & 117 & 117 & 206 & 206 & 227 & 227 & 157 & 157 \\
\hline 2 & 30 & 60 & 48 & 96 & 42 & 84 & 31 & 62 \\
\hline 3 & 6 & 18 & 15 & 45 & 18 & 54 & 9 & 27 \\
\hline 4 & 8 & 32 & 7 & 28 & 4 & 16 & 5 & 20 \\
\hline 5 & 3 & 15 & 3 & 15 & 5 & 25 & 6 & 30 \\
\hline 6 & 3 & 18 & 3 & 18 & 5 & 30 & 2 & 12 \\
\hline 7 & 1 & 7 & 2 & 14 & 3 & 21 & 2 & 14 \\
\hline 8 & 0 & 0 & 2 & 16 & 4 & 32 & 5 & 40 \\
\hline 9 & 0 & 0 & 1 & 9 & 2 & 18 & 2 & 18 \\
\hline 10 & 2 & 20 & 3 & 30 & 0 & 0 & 1 & 10 \\
\hline 11 & 0 & 0 & 0 & 0 & 2 & 22 & 5 & 55 \\
\hline 12 & 0 & 0 & 1 & 12 & 0 & 0 & 2 & 24 \\
\hline 14 & 1 & 14 & 0 & 0 & 0 & 0 & 0 & 0 \\
\hline 15 & 0 & 0 & 0 & 0 & 0 & 0 & 1 & 15 \\
\hline 16 & 0 & 0 & 0 & 0 & 0 & 0 & 1 & 16 \\
\hline 20 & 0 & 0 & 1 & 20 & 2 & 40 & 0 & 0 \\
\hline 26 & 0 & 0 & 0 & 0 & 0 & 0 & 1 & 26 \\
\hline 32 & 0 & 0 & 0 & 0 & 1 & 32 & 0 & 0 \\
\hline 55 & 0 & 0 & 0 & 0 & 0 & 0 & 1 & 55 \\
\hline 96 & 0 & 0 & 0 & 0 & 0 & 0 & 1 & 96 \\
\hline Total & 171 & 301 & 292 & 509 & 315 & 601 & 232 & 677 \\
\hline
\end{tabular}

Table 2. Number of bulk tank milk samples tested in each dairy cattle shed

\begin{tabular}{lll}
\hline \hline $\begin{array}{l}\text { Number of samples from } \\
\text { one shed }\end{array}$ & $\begin{array}{l}\text { Number of } \\
\text { sheds }\end{array}$ & $\begin{array}{l}\text { Total number } \\
\text { of samples }\end{array}$ \\
\hline 1 & 214 & 214 \\
2 & 20 & 40 \\
3 & 7 & 21 \\
4 & 4 & 16 \\
6 & 1 & 6 \\
7 & 3 & 21 \\
9 & 2 & 18 \\
10 & 1 & 10 \\
Total & 252 & 346 \\
\hline \hline
\end{tabular}

(qPCR). For this purpose, the Rotor-gene Q 5plex real-time PCR instrument (Qiagen, Germany) and the Adiavet Cox Realtime qPCR kit (Adiagene, France) that targets the IS1111 DNA sequence were used according to manufacturers' instructions. DNA for qPCR was extracted manually with the QIAamp DNA Mini kit (Qiagen, Germany) according to the protocol supplied with Cox Realtime qPCR kit.

All blood samples and BTM samples were screened for the presence of anti- $C$. burnetii antibodies by enzyme-linked immunosorbent assay (ELISA) using the ID screen Q fever indirect multi-species kit (IDvet, France). The results for each bulk milk and blood sample were interpreted according to the manual provided by the manufacturer.

\section{Spatial clustering analysis}

Data of C. burnetii DNA and antibody presence in BTM samples was used to identify regions of increased risk of $C$. burnetii infection. Data of $C$. burnetii antibody presence in blood serum samples were used to detect spatial clusters of $C$. burnetii related abortion cases. A cattle shed from which the analysed BTM or blood serum sample had originated was considered a unit of analysis for a spatial scan statistics analysis. Geographical location data for cattle sheds were derived from the Agricultural Data Centre of the Republic of Latvia. Detection of spatial clustering of test-positive cattle sheds in each year was performed using SaTScan v.9.3. software [24] using Bernoulli probability model scanning for high and low-rate $C$. burnetii agent and antibody occurrence circular clusters [25]. The maximal cluster size was 
set to $15 \%$ of population at risk according to an average herd level $C$. burnetii infection prevalence of the analysed dairy cattle population. Hypothesis testing of $P$ values for randomised $v s$. real cluster formation were based on the standard Monte Carlo method with 999 permutations.

Results of spatial clustering and spatial distribution of $C$. burnetii infections were visualised using software QGIS 2·12·2. [26].

\section{Risk factor analysis}

For risk factor analysis, ' $C$. burnetii positive/negative shed' was used as a dependent variable. C. burnetii DNA presence was assessed in BTM samples analysed with qPCR and the shed was considered as $C$. burnetii positive if $C$. burnetii DNA was detected in at least one BTM sample from the shed. The risk for a shed to be identified as $C$. burnetii positive in association with 13 risk factors was analysed using univariable logistic regression calculation with software MedCalc 16:8.4. [27]. The following risk factors were included in the univariable analysis: (1) sample size representing number of animals included in the sample, (2) number of cattle in the shed from which BTM was collected, (3) number of sheep in the shed from which BTM was collected, (4) indegree - number of cattle sheds from which the analysed shed has received animals during the 2 year period (20132015) prior to the analysis, (5) cattle from abroad represents number of animals purchased from abroad during the 2 year period prior to the analysis (country representation in cases of cattle purchase from abroad is indicated in Table 3), (6) shed density represents average number of cattle sheds $/ \mathrm{km}^{2}$ of local municipality (in total there are 110 local municipalities in Latvia with average area of $580 \mathrm{~km}^{2}$ ) as on 1 January 2015, (7) cattle density representing number of cattle $/ \mathrm{km}^{2}$ of local municipality, (8) heifer and cow density (number of heifers and cows $/ \mathrm{km}^{2}$ ), (9) cow density (number of cows $/ \mathrm{km}^{2}$ ), (10) sheep density (number of sheep $/ \mathrm{km}^{2}$ ), (11) goat density (number of goats $/ \mathrm{km}^{2}$ ), (12) average wind speed $\mathrm{m} / \mathrm{s}$ - represents average wind speed of the driest month of 1 year period prior to the analysis at the meteorological station closest to the analysed cattle shed, (13) localisation of the sample with regard to the region of increased risk determined by SaTScan analysis (Northern Latvia). Data of animal numbers, shed numbers and animal movements was retrieved from the Agricultural Data Centre of the Republic of Latvia, data of wind
Table 3. Countries of origin of cattle purchased from abroad in Latvian dairy cattle sheds included in the analysis of bulk tank milk for presence of Coxiella burnetii $D N A$

\begin{tabular}{ll}
\hline \hline $\begin{array}{l}\text { Country of origin of cattle } \\
\text { purchased from abroad }\end{array}$ & $\begin{array}{l}\text { Number of sheds introducing } \\
\text { cattle from abroad }\end{array}$ \\
\hline Germany & 11 \\
The Netherlands & 5 \\
Denmark & 2 \\
Estonia & 3 \\
Finland & 1 \\
Sweden & 1 \\
Lithuania & 1 \\
Czech Republic & 1 \\
\hline \hline
\end{tabular}

speed and precipitation was derived from Latvian Environment, Geology and Meteorology Centre open access data [28]. Variables representing animal and shed density and average wind speed were entered in the analysis in form of continuous data. For the purposes of analysis numerical variable 'sample size' was catgorised based on quartiles using MedCalc 16.8.4. [27]. Variables 'number of cattle in the shed' and 'indegree' were categorised into biologically meaningful categories. Principal component analysis (PCA) including all variables of $P<0 \cdot 2$ from the univariable logistic regression was performed using FactoMineR package [29] of $\mathrm{R}$ software version 3.2.3. [30] to elucidate colinearity of predictor variables. Classification of variables 'Sample size', 'number of cattle in the shed' used in the univariable logistic regression was not maintained for PCA, variables have been included in PCA as numerical variables. The PCA including nine variables of $P<0 \cdot 2$ from the univariable logistic regression identified two groups of collinear variables: (1) cattle density, cow density and heifer plus cow density, (2) cattle in the shed and sample size (Fig. 1). From pairs of collinear variables predictors with the highest correlation with corresponding principal component were chosen for a final multivariable model. Variable 'localisation of the sample' was included in the multivariate model without testing by PCA since it was a variable of a particular interest for authors. Multivariable logistic regression model building was performed using backward selection procedure with MedCalc 16.8.4. [27] including significant (univariable logistic regression $P<0 \cdot 2$ ) noncollinear variables. Variables were entered in the model if $P<0.05$ and removed from the model if $P>0 \cdot 1$. Variables 'cow plus heifer density', 'shed density' and 'wind speed' did not satisfy settings of multivariable 


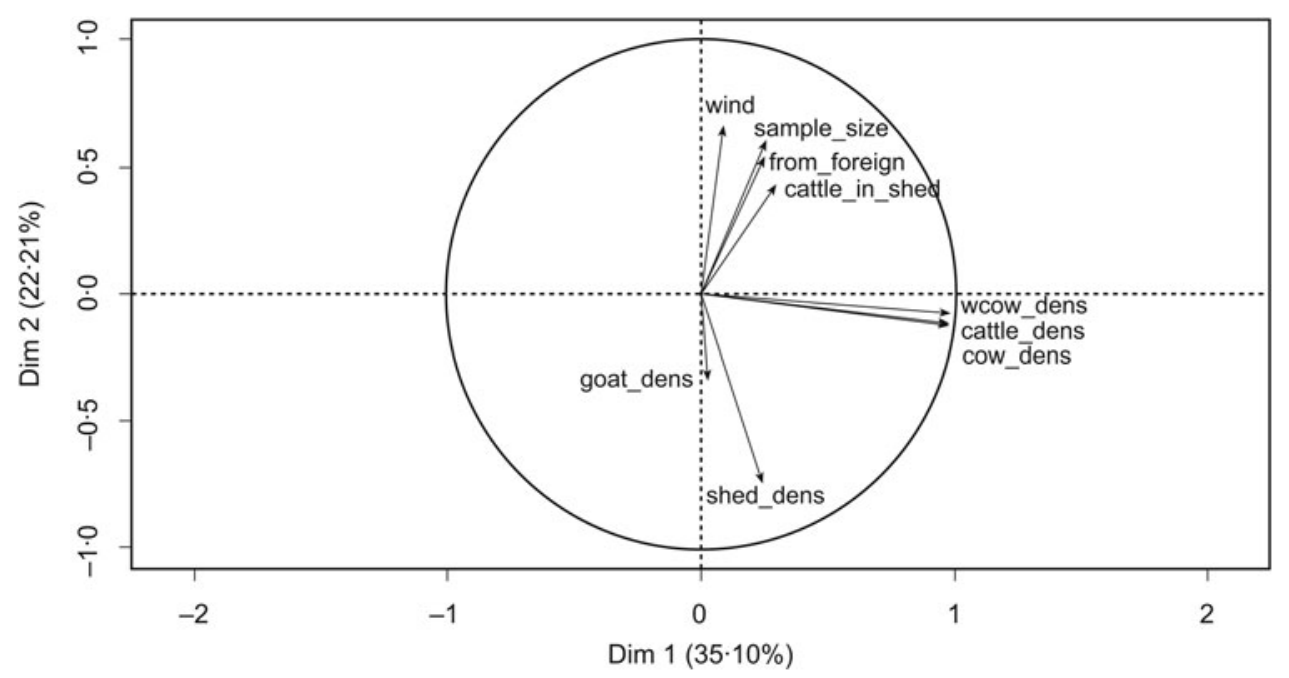

Fig. 1. Principal component analysis including predictor variables identified in univariable logistic regression analysis as significantly (Wald's $P<0.05$ ) associated with increased risk of Coxiella burnetii DNA presence in bulk tank milk (BTM).

logistic regression model backward selection procedure and were excluded. Validity of a multivariable logistic regression model was assessed by the likelihood ratio test, the Hosmer-Lemeshow test for global goodness of fit (GOF) and receiver operating characteristic curve using MedCalc 16·8·4. [27].

\section{RESULTS}

\section{Prevalence of $Q$ fever in dairy cows}

A total of $13 \cdot 4 \%$ (95\% confidence interval (CI) $9 \cdot 9$ 16.9) of cow sheds included in the national abortion surveillance programme tested positive for the presence of $C$. burnetii antibodies in blood serum of dairy cows sampled in cases of abortion. At the individual level, on average $27 \cdot 0 \%$ (95\% CI $19 \cdot 8-33 \cdot 2)$ of tested animals contained $C$. burnetii antibodies in blood serum after abortion.

In $10 \cdot 7 \%(95 \%$ CI $7 \cdot 2-14 \cdot 2 \%)$ of cow sheds at least one BTM sample tested positive for $C$. burnetii DNA and $13 \cdot 2 \%(95 \%$ CI $7 \cdot 9-18 \cdot 5 \%)$ of sheds tested positive for presence of antibodies to C. burnetii in milk. For $91 \%$ of BTM samples tested the result was identical for both indicators $-C$. burnetii DNA and $C$. burnetii antibodies, suggesting high diagnostic agreement between both analyses (Table 4).

\section{Spatial distribution of dairy cow sheds with $C$. burnetii infected animals}

Based on data of $C$. burnetii antibody presence in blood serum samples from abortion cases spatial epidemiology scan statistics identified increased risk
Table 4. Prevalence of Coxiella burnetii antibodies and $\mathrm{C}$. burnetii DNA in Latvian dairy cow BTM samples $(n=346)$ tested by ELISA and real time PCR

\begin{tabular}{|c|c|c|c|c|}
\hline & & \multicolumn{3}{|c|}{$\begin{array}{l}\text { Number of samples } \\
\text { analysed by ELISA }\end{array}$} \\
\hline & & Positive & Negative & Total \\
\hline \multirow{3}{*}{$\begin{array}{l}\text { Number of samples } \\
\text { analysed by real time } \\
\text { PCR }\end{array}$} & Positive & 46 & 5 & 51 \\
\hline & Negative & 23 & 272 & 295 \\
\hline & Total & 69 & 277 & 346 \\
\hline
\end{tabular}

BTM, bulk tank milk; PCR, polymerase chain reaction.

clusters of $C$. burnetii infected dairy cow sheds in the South-Central part of Latvia (Fig. 2). A single high risk cluster was detected for each year of the study 2012-2015 (maximum likelihood ratio test $P$ values $P=0.007,0.001,0.005$ for years 2012, 2014 and 2015, respectively), except for 2013. Circular areas of all identified clusters were partially overlapping.

High rate clusters of $C$. burnetii infected dairy cow sheds were also detected based on presence of $C$. burnetii DNA $(P=0 \cdot 002)$ and $C$. burnetii antibodies $(P=0 \cdot 001)$ in BTM samples (Fig. 3). Identified clusters had overlapping areas and were located in the Northern part of Latvia.

\section{Risk factor analysis}

From 13 variables analysed, 10 were identified by a univariable logistic regression as significantly associated $(P<0 \cdot 2)$ with presence of $C$. burnetii DNA in BTM (Table 5). Seven of 10 significant variables 


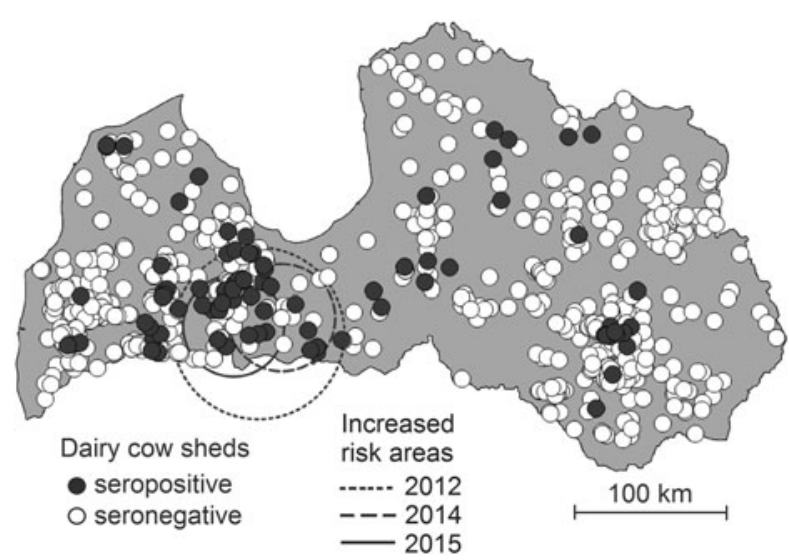

Fig. 2. Spatial distribution of dairy cow sheds sampled during 2012-2015 under the national programme of cow abortion surveillance for Coxiella burnetii antibodies in blood serum of dairy cows after abortions. Areas of increased risk to detect $C$. burnetii antibodies in blood serum samples are indicated.

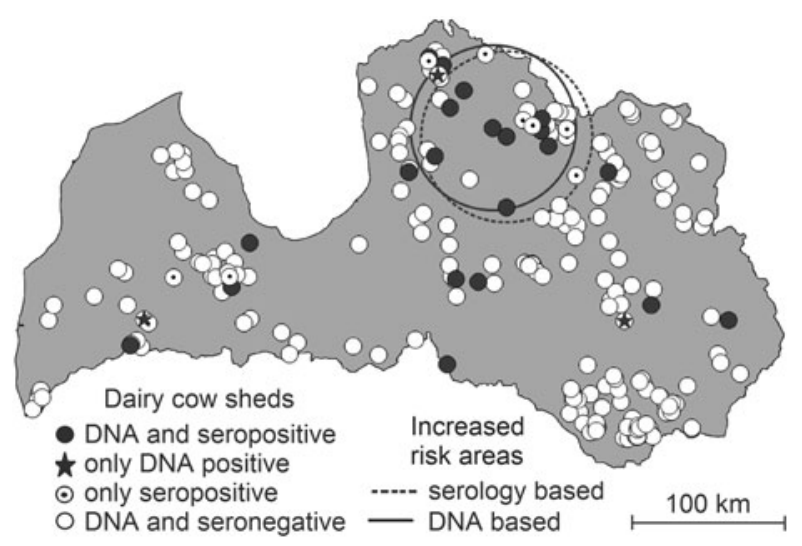

Fig. 3. Dairy cow sheds analysed for Coxiella burnetii DNA and C. burnetii antibody presence in bulk tank milk (BTM) samples in 2015. Areas of increased risk to detect C. burnetii DNA or C. burnetii antibodies in BTM are indicated.

from univariable regression were used for multivariable logistic regression model building.

Multivariable logistic regression using backward selection procedure included four from seven tested variables in the final multivariable model (Table 6). Three from four variables included in the final model showed significant positive association with C. burnetii DNA presence in BTM samples - cattle number in the shed, purchasing animals from abroad and localisation within the area of increased risk as determined by SaTScan analysis (Table 6). Large dairy cattle sheds (with more than 200 cows) holding cattle purchased from abroad and located in increased risk region of Northern Latvia are at significantly higher risk of acquiring C. burnetii infection. The final multivariable logistic regression model of four variables satisfied statistical requirements - likelihood ratio test confirmed overall significance of the model $(P<0 \cdot 0001)$, the model fitted the data (Hosmer and Lemeshow GOF test did not allow for rejection of the model, $P=0.5198$ ) and had good predictive ability as assessed by ROC curve (area under the curve $=$ $0 \cdot 820,95 \%$ CI $76 \cdot 6-86 \cdot 5 \%$ ).

\section{DISCUSSION}

To the best of our knowledge, this is the first study assessing prevalence and spatial spread of Q fever in dairy cows in any of Baltic countries and analysing underlying risk factors.

In the present study a total of $13 \cdot 2 \%$ (95\% CI $7 \cdot 9$ $18 \cdot 5 \%$ ) of tested Latvian dairy cattle sheds hold cows of either present or recent $C$. burnetii infection as estimated by presence of $C$. burnetii antibodies in BTM samples. Estimated C. burnetii prevalence in samples from abortion cases was almost identical to prevalence in randomly sampled BTM samples suggesting that significant contribution of $C$. burnetii infections to cattle abortions in the analysed cattle population is unlikely. Diagnosis via PCR for the presence of C. burnetii DNA in BTM estimated slightly lower prevalence of $10 \cdot 7 \%(95 \%$ CI $7 \cdot 2-14 \cdot 2 \%)$, which may suggest the immunological response is more enduring than the shedding of the causative agent into milk and shedding can be intermittent in cattle [31].

The estimated prevalence of $Q$ fever in Latvian dairy cows is close to the $8 \%$ herd level prevalence reported for Sweden [32] and considerably lower than the herd level prevalence reported in countries of western Europe $(82 \%$ in The Netherlands [18], $79 \%$ in Denmark [16], $72 \%$ in Germany [33] or $70 \%$ in Spain [34]) or central Europe (40\% in Poland [35]). Other countries of northern Europe have reported even lower levels of prevalence in dairy cattle herds $-0 \%$ in Norway [36] and $0 \cdot 24 \%$ in Finland [37] suggesting that in northern Europe C. burnetii infections of dairy cattle are significantly less common as opposed to western and central Europe. Unfortunately there are no data available regarding dairy cattle Q fever herd level prevalence in the two other Baltic countries - Estonia and Lithuania, however comparatively low $C$. burnetii prevalence in Latvian dairy cow population might indicate that North European region of low prevalence in dairy cattle extends to Baltic countries. 
Table 5. Univariable logistic regression analysis of risk factors associated with prevalence of Coxiella burnetii DNA in dairy cow BTM samples

\begin{tabular}{|c|c|c|c|c|}
\hline Variable & $\begin{array}{l}\text { No. of BTM } \\
\text { samples tested }\end{array}$ & No. positive $(\%)$ & OR $(95 \% \mathrm{CI})$ & $\begin{array}{l}\text { Wald's tes } \\
P \text { value }\end{array}$ \\
\hline Sample size & & & & $<0.0001 *$ \\
\hline$<10$ & 79 & $2(3)$ & Ref & \\
\hline $10-13$ & 47 & $1(2)$ & $0 \cdot 84(0 \cdot 07-9 \cdot 49)$ & $0 \cdot 8858$ \\
\hline $14-27$ & 61 & $6(10)$ & $4.20(0 \cdot 82-21 \cdot 59)$ & $0 \cdot 0005^{*}$ \\
\hline$>27$ & 63 & $18(29)$ & $14 \cdot 54(3.21-65 \cdot 88)$ & $<0 \cdot 0001$ \\
\hline Number of cattle in shed & & & & $<0 \cdot 0001^{*}$ \\
\hline$<200$ & 227 & $18(8)$ & Ref & \\
\hline$\geqslant 200$ & 23 & $9(39)$ & $7 \cdot 46(2 \cdot 84-19 \cdot 61)$ & $<0 \cdot 0001^{*}$ \\
\hline Number of sheep in shed & & & & $0 \cdot 4193$ \\
\hline Absent & 232 & $26(11)$ & Ref & \\
\hline Present & 18 & $1(6)$ & $0 \cdot 47(0 \cdot 06-3 \cdot 45)$ & $0 \cdot 47$ \\
\hline In-degree (2013-2015) & & & & $0 \cdot 5490$ \\
\hline 0 & 110 & $11(10)$ & Ref & \\
\hline $1-2$ & 95 & $9(10)$ & $0 \cdot 94(0 \cdot 37-2 \cdot 38)$ & $0 \cdot 8992$ \\
\hline$\geqslant 3$ & 45 & $7(16)$ & $1.66(0 \cdot 59-4.59)$ & $0 \cdot 3308$ \\
\hline Number of cattle from foreign & 250 & & $4.09(1.95-8.58)$ & $0 \cdot 0002 *$ \\
\hline Shed density (sheds $/ \mathrm{km}^{2 \mathrm{a}}$ ) & 250 & & $0 \cdot 11(0 \cdot 02-0 \cdot 80)$ & $0.0295^{*}$ \\
\hline Cattle density $\left(\right.$ cattle $/ \mathrm{km}^{2}$ ) & 250 & & $1 \cdot 12(1 \cdot 01-1 \cdot 25)$ & $0 \cdot 0304 *$ \\
\hline Cow density (cows/km²) & 250 & & $1.29(1.03-1 \cdot 60)$ & $0 \cdot 0246^{*}$ \\
\hline Cow and heifer density (number $/ \mathrm{km}^{2}$ ) & 250 & & $1 \cdot 15(1.03-1 \cdot 29)$ & $0 \cdot 0158^{*}$ \\
\hline Sheep density $\left(\right.$ sheep $/ \mathrm{km}^{2}$ ) & 250 & & $0.94(0.61-1.46)$ & $0 \cdot 7852$ \\
\hline Goat density (goats $/ \mathrm{km}^{2}$ ) & 250 & & $0.09(0.003-3.34)$ & $0 \cdot 1962$ \\
\hline Wind speed $\left(\mathrm{m} / \mathrm{s}^{\mathrm{b}}\right)$ & 250 & & $1 \cdot 71(0.95-3 \cdot 08)$ & $0 \cdot 0764$ \\
\hline Location regarding increased risk $\operatorname{area}^{\mathrm{c}}$ & & & & $<0 \cdot 0001^{*}$ \\
\hline Samples outside the region & 218 & $15(7)$ & Ref & \\
\hline Samples within the region & 32 & $12(38)$ & $8 \cdot 12(3 \cdot 34-19 \cdot 72)$ & $<0 \cdot 0001^{*}$ \\
\hline
\end{tabular}

BTM, bulk tank milk; CI, confidence interval; OR, odds ratio.

${ }^{a}$ All density related variables have been based on variable values of the corresponding municipality.

${ }^{\mathrm{b}}$ Average wind speed $\mathrm{m} / \mathrm{s}$ in the month with lowest overall precipitation.

${ }^{\mathrm{c}}$ Increased risk region located in Northern part of Latvia determined by SaTScan analysis.

*Statistically significant.

Table 6. Multivariable logistic regression analysis of risk factors associated with prevalence of Coxiella burnetii DNA in dairy cow BTM samples

\begin{tabular}{llll}
\hline \hline Variable & Category & OR $(95 \% \mathrm{CI})$ & Wald's test $P$ value \\
\hline Number of cattle in shed & & & \\
& $>200$ & Ref & - \\
& & $3 \cdot 93(1 \cdot 12-13 \cdot 81)$ & $0 \cdot 0329^{*}$ \\
Number of cattle from foreign & & $2 \cdot 68(1 \cdot 08-6 \cdot 69)$ & $0 \cdot 0345^{*}$ \\
${\text { Goat density (number per km }{ }^{2} \text { ) }}_{\text {Location regarding increased risk area }}{ }^{a}$ & & $0 \cdot 02(0 \cdot 0002-1 \cdot 02)$ & $0 \cdot 0511$ \\
& Outside & Ref & \\
& Inside & $8 \cdot 29(3 \cdot 09-22 \cdot 24)$ & $<0 \cdot 0001^{*}$ \\
\hline \hline
\end{tabular}

BTM, bulk tank milk; CI, confidence interval; OR, odds ratio.

${ }^{a}$ Increased risk region located in Northern part of Latvia determined by SaTScan analysis.

*Statistically significant. 
Spatial scan statistics analysis of $C$. burnetii infection prevalence in cases of dairy cow abortions identified regions of higher $C$. burnetiiinfection risk in south-central Latvia. This region is characterised by intensive dairy farming with farms holding comparatively larger numbers of dairy cattle and routinely introducing dairy cattle from abroad. Increased risk for $\mathrm{Q}$ fever spread in regions of intensified dairy cattle husbandry have previously been observed in Ireland [14], Denmark [16] and Sweden [20] and vaccination has been suggested as the most appropriate preventive measure restricting spread of $\mathrm{Q}$ fever in high-risk areas [20]. Interestingly, clustering of antibodypositive BTM samples and seropositive abortion cases occurred in two distinct regions. Such differences might be explained by a dissimilar role of $C$. burnetii in triggering cow abortions in both regions (probably caused by presence of different $C$. burnetii strains). However, further studies are required to confirm this hypothesis.

Multivariable regression analysis identified large cattle numbers in shed and localisation in North Latvia increased risk region as factors significantly contributing to increased risk of $C$. burnetii infection. Association between herd size, animal density and increased risk of C. burnetii infection is well known [14, 16, 18, 20]. However estimated herd size ( $>200$ animals) significantly increasing risk of infection in the Latvian dairy cow population considerably differed from the high risk herd size (>80 animals) reported for the Danish dairy cattle population [16], which is likely attributable to the higher overall prevalence of Q fever in Denmark. Significant country-to-country differences in border values of the identified risk factors suggest that local guidelines and preventive measures to restrict spread of $C$. burnetii infections can only partially be based on estimates from another region. Assessment of risk factors needs to be performed for each country individually to ensure correct identification of farms and areas subjected to the increased risk of $C$. burnetii infections.

Univariable logistic regression identified animal purchasing from abroad as significantly increasing risk of BTM to be $C$. burnetii DNA positive. Multivariable regression analysis confirmed animal purchasing from abroad as a factor significantly increasing risk of $C$. burnetii infection in Latvian dairy cattle. The majority of animals acquired from abroad in analysed dairy cattle farms have originated from heavily infected dairy cattle populations of Germany, Denmark and the Netherlands (Table 3). Animal movements have previously been identified as a factor significantly contributing to spread of dairy cattle $C$. burnetii infections in Sweden and Netherlands [13, 18]. Previously published studies of risk factors contributing to $C$. burnetii dairy cattle infections have analysed animal movements within countries. However, results of the current study indicate that cases of animal movement between countries, especially between regions of significantly different $C$. burnetii prevalence, need to be subjected to additional control to restrict spread of $C$. burnetii infections in low prevalence regions. Risk factor analysis of $C$. burnetii antibodypositivity of Danish dairy cattle herds showed that quarantine of purchased animals can significantly reduce risk of introduction of C. burnetii infection [15]. Control measures including quarantine and $C$. burnetii infection diagnosis of cattle purchased from abroad could limit spread of $C$. burnetii infections and preserve low prevalence of $C$. burnetii infections in the Latvian dairy cattle herds.

\section{CONCLUSIONS}

Estimated prevalence of $C$. burnetii antibody and C. burnetii DNA positive herds in Latvia is comparatively low $(<15 \%)$. These results position Latvia among north-eastern European countries (as Sweden, Norway and Finland) with previously described low C. burnetii infection prevalence in dairy cattle. However, low prevalence status can be jeopardised by the practice of purchasing cattle from abroad, especially from heavily infected dairy cattle populations of Western Europe. Therefore, precautionary measures including quarantine and $C$. burnetii infection status identification need to be realised before introducing newly purchased cattle into herd.

\section{ACKNOWLEDGEMENTS}

We are very grateful to Assoc. prof Didzis Elferts for valuable comments on statistical analysis. We also thank anonymous reviewers for thoughtful comments. We acknowledge veterinary practitioners involved in sample collection. The study was financed by the Ministry of Agriculture of Latvia within the state budget program 20.02.00 Laboratory tests within the state surveillance of food chain and veterinary medicine.

\section{DECLARATION OF INTEREST}

None.

\section{REFERENCES}

1. EFSA, ECDC. The European Union summary report on trends and sources of zoonoses, zoonotic agents and foodborne outbreaks in 2013. EFSA Journal 2015; 13: 111. 
2. Gilsdorf A, et al. Large Q fever outbreak due to sheep farming near residential areas, Germany, 2005. Epidemiology and Infection 2008; 136: 1084-1087.

3. Schimmer B, et al. The use of a geographic information system to identify a dairy goat farm as the most likely source of an urban Q-fever outbreak. BMC Infectious Diseases 2010; 10: 69.

4. Wallensten A, et al. Q fever outbreak in Cheltenham, United Kingdom, in 2007 and the use of dispersion modelling to investigate the possibility of airborne spread. Euro Surveillance - European Communicable Disease Bulletin 2010; 15: 321-334.

5. Dijkstra F, et al. The 2007-2010 Q fever epidemic in The Netherlands: characteristics of notified acute Q fever patients and the association with dairy goat farming. FEMS Immunology \& Medical Microbiology 2012; 64: $3-12$.

6. Bielawska-Drózd A, et al. Q fever-selected issues. Annals of Agricultural and Environmental Medicine 2013; 20: 222-232.

7. Roest HIJ, et al. Search for possible additional reservoirs for human Q fever, The Netherlands. Emerging Infectious Diseases 2013; 19: 834-835.

8. Bosnjak E, et al. Emerging evidence for Q fever in humans in Denmark: role of contact with dairy cattle. Clinical Microbiology and Infection 2010; 16: 1285-1288.

9. Schimmer B, et al. Coxiella burnetii seroprevalence and risk for humans on dairy cattle farms, the Netherlands, 2010-2011. Emerging Infectious Diseases 2014; 20: 417-425.

10. Roest HIJ, et al. Q fever in pregnant goats: pathogenesis and excretion of Coxiella burnetii. PLoS ONE 2012; 7: e48949.

11. De Bruin A, et al. Detection of Coxiella burnetii DNA on small-ruminant farms during a $\mathrm{Q}$ fever outbreak in the Netherlands. Applied and Environmental Microbiology 2012; 78: 1652-1657.

12. Kersh GJ, et al. Presence and persistence of Coxiella burnetii in the environments of goat farms associated with a $\mathrm{Q}$ fever outbreak. Applied and Environmental Microbiology 2013; 79: 1697-1703.

13. Nusinovici S, et al. Relative contributions of neighbourhood and animal movements to Coxiella burnetii infection in dairy cattle herds. Geospatial Health 2014; 8: 471-477.

14. McCaughey C, et al. Coxiella burnetii ( $Q$ fever) seroprevalence in cattle. Epidemiology and Infection 2010; 138: 21-27.

15. Paul S, et al. Factors associated with Coxiella burnetii antibody positivity in Danish dairy cows. Preventive Veterinary Medicine 2012; 107: 57-64.

16. Agger JF, Paul S. Increasing prevalence of Coxiella burnetii seropositive Danish dairy cattle herds. Acta Veterinaria Scandinavica 2014; 56: 46.

17. Capuano F, Landolfi MC, Monetti DM. Influence of three types of farm management on the seroprevalence of $\mathrm{Q}$ fever as assessed by an indirect immunofluorescence assay. Veterinary Record 2001; 149: 669-671.

18. van Engelen E, et al. Prevalence and risk factors for Coxiella burnetii (Q fever) in Dutch dairy cattle herds based on bulk tank milk testing. Preventive Veterinary Medicine 2014; 117: 103-109.

19. Agger JF, et al. Risk factors for Coxiella burnetii antibodies in bulk tank milk from Danish dairy herds. Acta Veterinaria Scandinavica 2013; 55: 80.
20. Nusinovici S, et al. Q fever infection in dairy cattle herds: increased risk with high wind speed and low preciptation. Epidemiology and Infections 2015; 143: 33163326.

21. van der Hoek W, et al. Q fever in The Netherlands: the role of local environmental conditions. International Journal of Environmental Health Research 2011; 21: 441-451.

22. Agriculture Data Centre Republic of Latvia database (http://www.ldc.gov.lv/en). Accessed January 2016.

23. EFSA (European Food Safety Authority), ECDC (European Centre for Disease Prevention and Control). The European Union summary report on trends and sources of zoonoses, zoonotic agents and food-borne outbreaks in 2012. EFSA Journal 2014; 12: 234.

24. Kulldorff $M$ and Information Management Services. Inc. SaTScan ${ }^{\mathrm{TM}}$ v. 8.0: software for the spatial and spacetime scan statistics 2009. (http://www.satscan.org/). Accessed December 2015.

25. Kulldorff M. A spatial scan statistic. Communications in Statistics: Theory and Methods. 1997; 26: 1481-1496.

26. QGIS Development Team. QGIS geographic information system. Open source geospatial foundation project 2015. (http://qgis.osgeo.org). Accessed January 2016.

27. MedCalc. MedCalc Software bvba, Ostend, Belgium. (https://www.medcalc.org). Accessed October 2016.

28. Latvian Environment, Geology and Meteorology centre database (http://www.meteo.lv/meteorologija-datu-meklesana/?nid=461). Accessed December 2015.

29. Husson F, et al. FactoMineR: multivariate exploratory data analysis and data mining with R. 2014. R package version 1.32. (http://CRAN.R-project.org/package= FactoMineR). Accessed Januray 2016.

30. R Core Team. $R$ : A Language and Environment for Statistical Computing. R Foundation for Statistical Computing, Vienna, Austria. (http://www.R-project. org/). Accessed December 2015.

31. Guatteo R, et al. Coxiella burnetii shedding by dairy cows. Veterinary Research, 2007; 38: 849-860.

32. Ohlson A, et al. Surveys on Coxiella burnetii infections in Swedish cattle, sheep, goats and moose. Acta Veterinaria Scandinavica, 2014; 56: 39.

33. Böttcher $\mathbf{J}$, et al. Insights into the dynamics of endemic Coxiella burnetii infection in cattle by application of phase-specific ELISAs in an infected dairy herd. Veterinary Microbiology 2011; 151: 291-300.

34. Astobiza I, et al. Estimation of Coxiella burnetii prevalence in dairy cattle in intensive systems by serological and molecular analyses of bulk-tank milk samples. Journal of Dairy Science 2012; 95: 1632-1638.

35. Jodełko A, Niemczuk K, Szymańska-Czerwińska $M$. Seroprevalence of Coxiella burnetii in Polish cattle herds. Bulletin of the Veterinary Institute in Pulawy 2015; 59: 479-482.

36. Kampen AH, et al. No indication of Coxiella burnetii infection in Norwegian farmed ruminants. BMC Veterinary Research 2012; 8: 59.

37. Finnish Food Safety Authority (EVIRA) website (http:// www.evira.fi/portal//en/animals/current+issues/archive/? bid=1744). Accessed 6 March 2016. 